\title{
Treatment of experienced and naïve patients with hepatitis C: focus on telaprevir
}

\author{
This article was published in the following Dove Press journal: \\ Biologics:Targets and Therapy \\ 17 October 2012 \\ Number of times this article has been viewed
}

\author{
Roberta D'Ambrosio \\ Alessio Aghemo \\ Massimo Colombo \\ Centro A.M. e A. Migliavacca, \\ First Division of Gastroenterology, \\ Fondazione IRCCS Cà Granda \\ Ospedale Maggiore Policlinico, \\ Università degli Studi di Milano, \\ Milan, Italy
}

Correspondence: Massimo Colombo First Division of Gastroenterology, Fondazione IRCCS Cà Granda Ospedale Maggiore Policlinico, Università degli Studi di Milano, Via F Sforza 35, 20122 Milan, Italy

Tel +390255035432

Fax +390250320410

Email massimo.colombo@unimi.it

\begin{abstract}
Telaprevir (TVR) is an orally available protease inhibitor of the hepatitis $\mathrm{C}$ virus that in association with pegylated interferon and ribavirin (PR) was shown to improve the rates of sustained virological response and potentially reduce treatment duration in adult patients with chronic hepatitis C genotype. Despite its robust activity in both treatmentnaïve and experienced patients, the addition of TVR to PR is counterbalanced by increased costs and adverse events; moreover, there are still areas of uncertainty that regard treatment of patients with advanced liver disease, the role of patient stratification by genetic predictors, and the use/need for a lead-in phase with PR. Since TVR regimens have been associated with the risk of viral mutants that may cause treatment failure and jeopardize future therapeutic strategies with direct-acting antiviral agents, early stopping rules have been designed to protect patients with a poor virological response to TVR regimens against such a risk.
\end{abstract}

Keywords: protease inhibitor, pegylated interferon, ribavirin

\section{Introduction}

Chronic infection with the hepatitis $\mathrm{C}$ virus $(\mathrm{HCV})$ is a major cause of liver-related invalidity and mortality worldwide. In the USA, more than $1.3 \%$ of the population is chronically infected by HCV, generating a cost of $\$ 5.5$ billion annually. ${ }^{1}$ Successful antiviral treatment (sustained virological response [SVR]) following interferon-based regimens is the only approach to halting fibrosis progression and the inherent risk of end-stage liver disease. ${ }^{2-10}$

Until a few months ago, the current standard of care (SOC) of HCV was the combination of pegylated interferon alpha and ribavirin (PR), which has been associated with overall SVR rates of approximately $50 \%{ }^{11-13}$ in patients infected by the difficultto-cure HCV genotypes 1 and 4 , and with around $80 \%$ of the easier-to-cure HCV genotypes 2 and 3, leaving, therefore, a significant number of patients with a treatment failure, at risk of hepatitis progression.

Telaprevir (TVR) is a recently approved protease inhibitor of HCV that has been demonstrated, in association with PR, to improve SVR rates among adult patients chronically infected with genotype 1 of HCV. ${ }^{14-19}$ TVR and PR treatment is effective in both naïve and treatment-experienced patients. The reanalysis of registration trials and initial experience with patients in field practice have highlighted some areas of uncertainties that are commented on here. 


\section{HCV life cycle and TVR targets}

The life cycle of HCV begins with the virus's entry into the hepatocyte via receptor-mediated endocytosis, to be followed by virus uncoating and the consequent release of singlestranded HCV-RNA in the cytosol. In the cytosol, HCV-RNA is translated via the internal ribosome entry site, into a single large polyprotein that is cleaved by both viral and cellular proteases into at least ten different proteins. The first portion of the virus genome encodes structural proteins of HCV-like core, E1 and E2, whereas at least five nonstructural (NS) proteins constitute the $\mathrm{HCV}$ replicase system, including the NS3 protein. This is a multifunctional enzyme of strategic importance that includes a serine protease and a helicase domain coupled with the cofactor NS4A protein to form a stable NS3/4A complex. The NS3/4A serine protease, in fact, catalyzes $\mathrm{HCV}$ polyprotein cleavage to allow maturation of the virion, because viral replication is largely mediated by the NS5A and NS5B proteins, ${ }^{20-22}$ while it also interferes with cellular mechanisms of innate immunity related to interferon signaling.

\section{TVR pharmacological properties}

TVR is a linear peptidomimetic inhibitor of the NS3/4A serine protease, its function relying on the establishment of a stable but reversible covalent bond with proteolitic enzyme. TVR is rapidly absorbed through the small intestine (its half-life is about 58 minutes), and taken up by the liver on its first-pass metabolism to give high liver concentrations. ${ }^{23}$ Since the systemic exposure to TVR increases by $237 \%$ when the drug is administered with a standard fat meal, compared with fasting, TVR should be taken with food containing at least $20 \mathrm{~g}$ of fat. TVR is a substrate and an inhibitor of cytochrome P450 3A4 (CYP3A4), moderately binds to plasma proteins (ie, alpha-1-acid glycoprotein and albumin), and is predominantly eliminated in the feces $(>80 \%)$, with only minimal renal excretion $(<1 \%)$.

\section{Lessons from Phase I studies}

Monotherapy with TVR caused a rapid decline of viremia in the first days of dosing as a consequence of suppressed synthesis ofTVR-sensitive virions, but it was soon followed by a rebound of viremia between day 3 and 14 of dosing, due to the rapid selection of resistant-associated variants (RAV) that naturally occur in all $\mathrm{HCV}$-infected individuals. ${ }^{24} \mathrm{Upon}$ TVR withdrawal, the initial HCV RNA viremia was completely restored in a couple of weeks as a consequence of the emergence of wild-type HCV virions no longer exposed to the suppressive activity of TVR. The coadministration of PR led to the full suppression of TVR-related RAVs, consequently making serum HCV RNA undetectable in all treated patients. This was the proof of concept that the anti-HCV activity of TVR can be granted by the association with a PR backbone only, thereby providing the foundation for the Phase II and III studies in both naïve and treatmentexperienced patients.

\section{Treatment of naïve patients}

PR treatment of naïve patients with chronic hepatitis C genotype 1 led to SVR rates of approximately $50 \%{ }^{11-13}$ with substantial differences, according to the IL28B genotypes ( $80 \%$ in CC vs $40 \%$ in non-CC), liver fibrosis stage, and initial viremia. ${ }^{25-27}$ Phase II ${ }^{14,15}$ and Phase III studies ${ }^{17,18}$ provided clear evidences for the superiority of TVR combined with PR in the treatment of this patient population, both in terms of SVR rates and duration of therapy.

In the Phase II PROtease Inhibition for Viral Eradication (PROVE) trials $11^{14}$ and $2,{ }^{15}$ the efficacy and safety of TVR was assessed in association with PR in genotype 1a and $1 \mathrm{~b}$ patients with mild to moderate liver disease only, since patients with bridging fibrosis or cirrhosis were excluded.

The PROVE-1 trial ${ }^{14}$ (Table 1) was conducted in the USA on $250 \mathrm{HCV}-1$ naïve patients who were randomized to receive TVR (or placebo) according to one of the following arms: group 1 received T12PR24 (TVR $+\mathrm{P}+\mathrm{R}$ for 12 weeks, followed by $\mathrm{P}+\mathrm{R}$ for 12 weeks); group 2 received T12PR48 (TVR + P + R for 12 weeks, followed by P + R

Table I Rates of SVR in the Phase II and Phase III trials among treatment-naïve patients with genotype I infection

\begin{tabular}{|c|c|c|c|c|c|}
\hline Study & Phase & $\begin{array}{l}\text { Treated } \\
\text { patients }\end{array}$ & $\geq \mathbf{F 3 / F 4}$ & $\begin{array}{l}\text { Treatment } \\
\text { arms }\end{array}$ & SVR (\%) \\
\hline \multirow[t]{4}{*}{ PROVE-I } & $2 b$ & 250 & 0 & TI2PR24 & $48(6 \mathrm{I})$ \\
\hline & & & & TI2PR48 & $53(67)$ \\
\hline & & & & TI2PRI2 & $6(35)$ \\
\hline & & & & PR48 & $3 I(4 I)$ \\
\hline \multirow[t]{4}{*}{ PROVE-2 } & $2 b$ & 323 & 0 & TI2PR24 & $56(69)$ \\
\hline & & & & TI2PRI2 & $49(60)$ \\
\hline & & & & TI2PI2 & $28(36)$ \\
\hline & & & & PR48 & $38(46)$ \\
\hline \multirow[t]{3}{*}{ ADVANCE } & 3 & 1088 & $231 / 68$ & TI2PR & $27 \mid(75)$ \\
\hline & & & & T8PR & $250(69)$ \\
\hline & & & & PR48 & $158(44)$ \\
\hline \multirow[t]{6}{*}{ ILLUMINATE } & 3 & 540 & $|49 / 6|$ & TI2PR24 & 149 (92) \\
\hline & & & & (eRVR) & $140(88)$ \\
\hline & & & & TI2PR48 & $76(64)$ \\
\hline & & & & (eRVR) & \\
\hline & & & & TI2PR48 & \\
\hline & & & & (no eRVR) & \\
\hline
\end{tabular}

Abbreviations: SVR, sustained virological response; eRVR, extended rapid virological response. 
for 36 weeks); group 3 received T12PR12 (TVR + P + R for 12 weeks); and group 4 (control arm) received PR48 (placebo $+\mathrm{P}+\mathrm{R}$ for 12 weeks, followed by $\mathrm{P}+\mathrm{R}$ for 36 weeks). Patients in the T12PR24 and in the T12PR12 groups having a rapid virological response (RVR) were allocated to stop therapy at week 24 or 12 , respectively; the SVR rates were $61 \%$ in the T12PR24 group, $67 \%$ in the T12PR48 group, $35 \%$ in the T12PR 12 group, and $41 \%$ in the PR48 group. These higher SVR rates among patients in the TVR arms were the consequence of the higher RVR rates among these patients (ie, $81 \%$ in the T12PR24, $81 \%$ in the T12PR48, and $59 \%$ in the T12PR 12 vs 35\% in the PR 48 arms). The optimal dosing was for the groups T12PR24 and T12PR48, who had rates of relapse of $2 \%$ and $6 \%$, respectively. According to this study, however, the efficacy of a 24-week treatment in RVR patients was clearly demonstrated, thus building the basis for a response-guided therapy (RGT), whereas it demonstrated different responses to TVR by patients infected with subtype 1a or $1 \mathrm{~b}$, as a consequence of different rates of RAV-related virological failures.

The PROVE-2 study $^{15}$ (Table 1) confirmed high SVR rates among a similar cohort of European patients, who were randomly assigned to one of the following treatment arms: group 1 received T12PR24 (TVR $+\mathrm{P}+\mathrm{R}$ for 12 weeks, followed by $\mathrm{P}+\mathrm{R}$ for 12 weeks); group 2 received T12PR12 (TVR $+\mathrm{P}+\mathrm{R}$ for 12 weeks); group 3 received T12P12 (TVR + P for 12 weeks, without RBV); and group 4 (control arm) received PR48 (placebo $+\mathrm{P}+\mathrm{R}$ for 12 weeks, followed by $\mathrm{P}+\mathrm{R}$ for 36 weeks). Patients in the T12PR24, T12PR12 and T12P12 were not required to have a RVR, but HCV-RNA had to test negative at week 20 (T12PR24) and week 10 (T12PR12, T12P12) to stop treatment. SVR rates were significantly higher among patients treated with the triple regimen $(69 \%$ in T12PR24 and 60\% in T12PR12) than among those treated with PR (38\%) or without R (36\%) as a consequence of high RVR rates, which were $69 \%$ in T12PR $24,80 \%$ in T12PR12, 50\% in T12P12, and 13\% in PR48. In the TVR groups, the higher rates of SVR were the consequence of reduced relapse rates, which were $14 \%$ in T12PR $24,30 \%$ in T12PR12, 48\% in T12P12, and 22\% in PR48. The PROVE-2, while confirming the effectiveness of TVR for treatment of naïve $\mathrm{HCV}-1$ patients, highlighted the importance of $\mathrm{R}$ in preventing viral breakthrough and relapse following TVR regimens.

The efficacy and safety of TVR regimens in treatmentnaïve subjects were evaluated in the ADVANCE and ILLUMINATE Phase III studies, which led to the registration of
TVR for the treatment of adult patients with chronic hepatitis C genotype 1.

In the ADVANCE ${ }^{17}$ study (Table 1), 1088 patients, including $21 \%$ with bridging fibrosis or cirrhosis, were randomized to three arms, including the SOC with PR for 48 weeks (control group, PR48) or to one of the two combination treatment arms including TVR plus PR. The study included an arm with 8-week TVR associated with PR aimed to reduce the incidence of TVR-related skin rash (T8PR). Treatment-naïve subjects who achieved undetectable levels of HCV RNA at week 4 that extended to week 12 (ie, extended rapid virological response [eRVR]) stopped therapy at study week 24 (ie, after an additional 12 or 16 weeks of PR, respectively); otherwise, they received PR up to a complete 48-week course of therapy. In ADVANCE, the SVR rates were $75 \%$ in T12PR and $69 \%$ in T8PR, compared to the $44 \%$ in the control arm receiving PR48. The RVR rates were $68 \%$ in T12PR, 67\% in T8PR, and 9\% in PR48; similarly, eRVR rates were higher among patients treated with TVR than in controls (58\% vs $57 \%$ vs $8 \%$ ). SVR rates in patients with an eRVR were $89 \%$ in T12PR, $83 \%$ in T8PR, and $97 \%$ in PR48, whereas in patients without an eRVR were $54 \%$ in T12PR, 50\% in T8PR, and 39\% in PR48. Interestingly, the ADVANCE study also included patients with advanced liver disease, among whom the SVR rates were attenuated, ie, 62\% in T12PR, 53\% in T8PR, and 33\% in PR48. In conclusion, the ADVANCE trial, while confirming high rates of SVR among patients exposed to TVR regimens, clearly suggested that 24 weeks of therapy could be sufficient to cure patients with an eRVR, mainly as a consequence of low rates of breakthrough and posttreatment relapse.

The ILLUMINATE trial ${ }^{18}$ was designed to investigate any additional benefit in extending therapy from 24 to 48 weeks in subjects with an eRVR exposed to TVR combination treatment. The answer was crystal clear, since the SVR rates were similar in patients randomized to 24 or 48 weeks of TVR, ie, $92 \%$ and $88 \%$, respectively. This was not true, however, for patients with advanced fibrosis who may benefit from prolonged exposure to PR in order to efficiently clear all the infected hepatocytes. This was the message from a post hoc analysis of 30 patients enrolled in the ILLUMINATE study ${ }^{28}$ who achieved higher rates of SVR by following a 36-week tail of PR to complete 12 weeks of RGT with TVR than by following a shorter consolidation tail of 12 weeks with PR only (92\% vs 67\%). These findings, while calling for confirmation in a larger series of patients, still provided the rationale for recommending an extended tail of PR in naïve patients with advanced fibrosis receiving TVR-based regimens. 


\section{Treatment of experienced patients}

Patients failing to achieve an SVR to PR represent the majority of HCV-1 infected patients being substantially refractory to retreatment with the SOC. ${ }^{29,30}$

The Phase II PROVE-3 trial $^{16}$ (Table 2) established the efficacy of the TVR regimen in HCV-1 patients with a treatment failure to PR. Patients were randomized to one of the following treatment arms: group 1 received T12PR24 (TVR + P + R for 12 weeks, followed by P + R for 12 weeks); group 2 received T24PR 48 (TVR $+\mathrm{P}+\mathrm{R}$ for 24 weeks followed by $\mathrm{P}+\mathrm{R}$ for 36 weeks); group 3 received T24P24 (TVR + P for 24 weeks, without R); and group 4 (control arm) received PR48 (placebo $+\mathrm{P}+\mathrm{R}$ for 48 weeks). The study enrolled previous nonresponders (57\%), relapsers (36\%), and patients with a virological breakthrough (7\%). The T12PR24 and T24PR48 regimens were most efficacious, providing SVR rates of $51 \%$ and $53 \%$, respectively, whereas SVR rates were lower among patients treated with prolonged TVR regimen (T24) due to increased rates of treatment discontinuation for TVR-related toxicities (24\%) and in controls receiving PR48 (14\%). Relapsers to a previous course of PR were better responders to any TVR-based regimens than were those with a previous nonresponse (SVR $69 \%$ vs $39 \%$ in T12PR $24,76 \%$ vs $38 \%$ in T24PR $48,42 \%$ vs $11 \%$ in T24P 24 ).

In the control group (PR48), the SVR rates were $20 \%$ among patients with a previous relapse and $9 \%$ among patients with a previous nonresponse. The clinical importance of the pattern of a previous response to PR in the achievement of an SVR to TVR was confirmed in the Phase III trial REALIZE ${ }^{19}$ (Table 2). Patients with a treatment failure to PR, including $26 \%$ with cirrhosis, were randomly assigned to one of the following treatment arms: T12PR48 (TVR $+\mathrm{P}+\mathrm{R}$ for 12 weeks, followed by $\mathrm{P}+\mathrm{R}$ for 36 weeks), lead-in T12PR48 (placebo + P + R for 12 weeks, followed

Table 2 Overall rates of SVR in the Phase II and Phase III trials among treatment-experienced patients with genotype I infection

\begin{tabular}{llllll}
\hline Study & Phase & $\begin{array}{l}\text { Treated } \\
\text { patients }\end{array}$ & $\geq$ F3/F4 & $\begin{array}{l}\text { Treatment } \\
\text { arms }\end{array}$ & SVR (\%) \\
\hline PROVE-3 & $2 b$ & 453 & NA/74 & TI2PR24 & $59(5 \mathrm{I})$ \\
& & & & T24PR48 & $60(53)$ \\
& & & & T24PR24 & $27(24)$ \\
& & & & PR48 & $16(14)$ \\
REALIZE & 3 & 662 & \multirow{2}{*}{$316 / 169$} & TI2PR48 & $171(64)$ \\
& & & & Lead-in & $175(66)$ \\
& & & & TI2PR48 & $22(17)$ \\
& & & & PR48 & \\
\hline
\end{tabular}

Abbreviation: SVR, sustained virological response. by TVR $+\mathrm{P}+\mathrm{R}$ for 12 weeks, and subsequently $\mathrm{P}+\mathrm{R}$ for 36 weeks), and PR48 (placebo $+\mathrm{P}+\mathrm{R}$ for 48 weeks). Overall, the SVR rates were higher among patients treated in the two TVR groups than in the control arm (64\% in T12PR 48 , $66 \%$ in lead-in T12PR 48 , and $17 \%$ in PR 48 , being $83 \%$, $88 \%$, and $24 \%$ among patients with a relapse, $41 \%, 41 \%$, and $9 \%$ among patients with a partial response [defined as a reduction of $2 \log _{10}$ in HCV-RNA after 12 weeks of therapy but with detectable HCV-RNA at week 24], and 29\%, $33 \%$, and 5\% among those with no response [defined as a reduction of less than $2 \log _{10}$ in HCV-RNA after 12 weeks of treatment]) (Table 3).

Of note, SVR rates were improved between patients with a lead-in phase of PR preceding T12PR48 and those who started all three drugs simultaneously (T12PR48). Once more, liver fibrosis did impact on a response to retreatment with TVR regimens of patients who had had either a partial or a null response to a prior treatment with PR. ${ }^{31}$ Indeed, in the face of patients with a relapse to a previous course of PR who achieved very high rates of SVR to triple therapy independently from the stage of fibrosis (F0-2, 86\% vs F3-4, $85 \%$, according to the METAVIR scoring system), ${ }^{32}$ the SVR rates to triple therapy in F3/F4 patients with a previous either null or partial response to PR were $25 \%$ and $42 \%$ only, respectively. Though the rates of SVR in these latter patients were four- to fivefold higher than in similar patients retreated with dual $\mathrm{PR}$, the success rates were definitively lower than in F0-F2 patients receiving triple therapy with TVR ( $41 \%$ and $72 \%$, respectively), further indicating the strategic importance of the pattern of a response to a previous course of PR in determining the success of a retreatment with triple therapy.

\section{New concepts in RGT}

The important concepts of eRVR and virological failure have been utilized to define RGT in patients exposed to TVR.

With an eRVR being undetectable HCV-RNA at weeks 4 and 12, in the ADVANCE study, patients who achieved an eRVR received shortened ( 24 weeks) treatment and reported SVR rates of $89 \%$ to T12PR 24 , whereas patients with detectable HCV-RNA either at week 4 or 12 were allocated to the 48-week duration regimen and achieved 54\% SVR rates. The ILLUMINATE trial, where patients with an eRVR were randomly assigned to the T12PR24 or T12PR48, could demonstrate the noninferiority of the former regimen with respect to the latter one. In parallel, the standard stopping rules were redefined to prevent RAV-related complications in refractory patients upon continued exposure to TVR. 
Table 3 Rates of SVR in the REALIZE among treatment-experienced patients with genotype I infection according to their previous response to PR

\begin{tabular}{|c|c|c|c|c|c|}
\hline Previous response to PR & Treatment arms & Patients & SVR (\%) & Relapse (\%) & Breakthrough (\%) \\
\hline \multirow[t]{3}{*}{ Relapse } & TI2PR48 & 145 & $121(83)$ & $10(7)$ & $2(I)$ \\
\hline & Lead-in TI2PR48 & $|4|$ & $124(88)$ & $9(7)$ & $I(I)$ \\
\hline & PR48 & 68 & $16(24)$ & $30(65)$ & $18(26)$ \\
\hline \multirow[t]{3}{*}{ Partial response } & TI2PR48 & 49 & $29(59)$ & $8(2 I)$ & $9(18)$ \\
\hline & Lead-in TI2PR48 & 48 & $26(54)$ & $9(25)$ & $9(19)$ \\
\hline & PR48 & 27 & $4(15)$ & 0 & $19(70)$ \\
\hline \multirow[t]{3}{*}{ Null response } & TI2PR48 & 72 & $21(29)$ & $8(27)$ & $4 \mid(57)$ \\
\hline & Lead-in TI2PR48 & 75 & $25(33)$ & $9(25)$ & $35(47)$ \\
\hline & PR48 & 37 & $2(5)$ & $3(60)$ & 31 (84) \\
\hline
\end{tabular}

Abbreviations: PR, pegylated interferon and ribavirin; SVR, sustained virological response.

In ADVANCE, stopping rules were discontinuation of TVR alone at week 4 in patients with $\mathrm{HCV}-\mathrm{RNA}>1000$ $\mathrm{IU} / \mathrm{mL}$, and discontinuation of all treatment at week 24 or thereafter in patients with $\mathrm{HCV}-\mathrm{RNA}<2 \log _{10}$. A virological failure was also a value of HCV - RNA $>1000$ $\mathrm{IU} / \mathrm{mL}$ at week 12 in patients with a decline of viremia of at least $2 \log _{10}$. In ADVANCE, ${ }^{17}$ virological failures were uncommon in patients exposed to TVR compared to controls ( $8 \%$ in T12PR vs $13 \%$ in T8PR vs $32 \%$ in PR). In ILLUMINATE,${ }^{18}$ virological failures were uncommon $(8 \%$ of the overall population) occurring in $2 \%$ of patients treated in the T12PR 24 group and in 3\% of the T12PR48 group treated with an eRVR.

\section{Safety and tolerability}

The adverse events (AEs) profile of TVR includes pruritus, rash, anemia, and gastrointestinal disorders (anorectal symptoms, diarrhea, and nausea). The incidence of AEs was higher in patients treated in the TVR arms than in control group
(Table 4) and was the cause of treatment discontinuation in approximately $5 \%$ of the treated patients.

While Phase II and III studies failed to provide information on the impact of AEs in patients with cirrhosis who were definitively under represented, the CUPIC study, related to the French early access program, and showed high rates $(60 \%)$ of serious AEs among cirrhotics treated with TVR during a median period of treatment of 3 months. ${ }^{33}$

\section{Anemia}

Anemia is a prevalent and relevant AE, its prevalence ranging between $8 \%$ and $42 \%$ in the different TVR arms, compared to $8 \%-27 \%$ in the PR group. Anemia is thought to be the result of bone-marrow suppression by PR, following a hemolytic hit by $\mathrm{R}$, with $\mathrm{Hb}$ values below $10 \mathrm{mg} / \mathrm{dL}$ being observed in approximately $40 \%$ of the patients exposed to TVR (Table 4). While erythropoietin (EPO) was generally prohibited both in Phase II and III trials, approximately 5\% of the patients with anemia had to be transfused, and $\mathrm{R}$ was

Table 4 Rates of the most frequent adverse events and treatment discontinuation among patients in the Phase II and Phase III trials

\begin{tabular}{|c|c|c|c|c|c|c|c|c|c|}
\hline Study & $\begin{array}{l}\text { Any } \\
\%\end{array}$ & $\begin{array}{l}\text { Fatigue } \\
\%\end{array}$ & $\begin{array}{l}\text { Nausea } \\
\%\end{array}$ & $\begin{array}{l}\text { Diarrhea } \\
\%\end{array}$ & $\begin{array}{l}\text { Anemia } \\
\%\end{array}$ & $\begin{array}{l}\text { Rash } \\
\%\end{array}$ & $\begin{array}{l}\text { Pruritus } \\
\%\end{array}$ & $\begin{array}{l}\text { Hemorrhoids } \\
\%\end{array}$ & $\begin{array}{l}\text { Treatment discontinuation } \\
\text { due to AEs (\%) }\end{array}$ \\
\hline \multicolumn{10}{|l|}{ PROVE-I } \\
\hline TVR arms & NA & $70-82$ & $48-65$ & $24-42$ & $29-37$ & $53-61$ & $10-18$ & $13-24$ & 21 \\
\hline Control arm & NA & 76 & 43 & 28 & 27 & $4 I$ & 0 & I & II \\
\hline \multicolumn{10}{|l|}{ PROVE-2 } \\
\hline TVR arms & $99-100$ & $26-33$ & $31-48$ & $25-32$ & $9-27$ & $47-49$ & $51-63$ & NA & 12 \\
\hline Control arm & 99 & 37 & 40 & 28 & 17 & 35 & 35 & NA & 7 \\
\hline \multicolumn{10}{|l|}{ PROVE-3 } \\
\hline TVR arms & NA & $46-67$ & $24-48$ & $26-43$ & $8-27$ & $4 I-60$ & $34-44$ & $13-17$ & $25-21$ \\
\hline Control arm & NA & 56 & 34 & 19 & 8 & 20 & 15 & 3 & 68 \\
\hline \multicolumn{10}{|l|}{ ADVANCE } \\
\hline TVR arms & 99 & $57-58$ & $40-43$ & $28-32$ & $37-39$ & $35-37$ & $45-50$ & NA & 10 \\
\hline Control arm & 98 & 57 & 31 & 22 & 19 & 24 & 36 & NA & 7 \\
\hline ILLUMINATE & $99-100$ & $68-69$ & $44-48$ & $30-34$ & $32-42$ & $37-40$ & $47-59$ & NA & NA \\
\hline
\end{tabular}

Note: In the ILLUMINATE trial, there is not a control group.

Abbreviations: $A E$, adverse event; TVR, telaprevir. 
reduced in approximately $25 \%$ of the patients. Interestingly, $\mathrm{R}$ dose reduction did not impact on the final SVR rates $(76 \%$ vs $72 \%$ ), with preliminary evidence being that SVR rates were higher in patients with $\mathrm{a}>3 \mathrm{~g} \mathrm{Hb}$ decline, compared to those with milder anemia. ${ }^{34}$ Surprisingly, in the CUPIC study, EPO was given to up $45 \%$ of the patients with cirrhosis, whereas blood transfusions were necessary in less than $17 \%{ }^{33}$ Nowadays, the clinical practice with EPO is regulated differently in each European community.

\section{Rash}

Rash frequently occurred in patients treated with TVR, the highest rates being $61 \%$ vs $41 \%$ in the control group (Table 4 ). The typical eczematous, maculopapular, and papularlichenoid rash develops within the first 4 weeks of treatment, resolving over 4-6 weeks after treatment completion. A severe rash, defined as involving $>50 \%$ of the body surface area or being associated with significant systemic symptoms, mucous membrane ulceration, target lesions, or epidermal detachment, occurred in approximately $5 \%$ of the subjects treated with TVR-regimens and $0.4 \%$ of the controls. Rash led to premature discontinuation of TVR alone in $6 \%$ of the patients, compared to no drug discontinuation among controls.

\section{Anorectal disorders}

Anorectal disorders, the direct consequence of TVR elimination through feces, develop within the first 15 days of treatment. Though the mechanisms responsible for anorectal disorders are still unknown, symptoms typically including hemorrhoids, anal pruritus, anal discomfort, or rectal burning, which occur in approximately $25 \%$ of the patients (Table 4 ). In all trials, symptoms have been described as mild to moderate, only occasionally leading to treatment discontinuation.

\section{RAV}

The very high replication rate of $\mathrm{HCV}$ and the lack of an effective proofreading mechanism account for nucleotide variants of $\mathrm{HCV}$ being generated in each patient at any time. RAVs are therefore present in $0.3 \%-2.8 \%$ of treatment-naïve subjects, rapidly emerging as dominant strains after initiation of treatment with TVR. ${ }^{35}$ The following variants, classified according to the position of substituted amino acids, have been reported in treatment-naïve patients: V36M $(0.9 \%)$, R155K (0.7\%), V170A (0.2\%), and R109K (0.2\%), ${ }^{36}$ with patients infected by HCV genotype 1a exhibiting a much higher prevalence of RAV compared to those infected with HCV genotype $1 \mathrm{~b}(8.6 \%$ vs $1.4 \%) .{ }^{14,37,38}$ In patients receiving TVR, TVR RAVs were observed in $12 \%$ of treatment-naïve patients and $22 \%$ of treatment-experienced groups, the greatest prevalence $(80 \%)$ of RAVs being reported in patients who did not achieve an SVR. Importantly, the proportion of RAV tends to decrease after TVR is stopped, variants being replaced by wild-type strains of $\mathrm{HCV}$ upon withdrawal of TVR selective pressure. ${ }^{39}$

\section{Drug-drug interactions}

Since TVR is at the same time a potent inhibitor and a metabolite of CYP3A4, coadministration of drugs metabolized along the same enzymatic pathway may result in TVR inactivation and increased exposure to coadministered drugs, with potentially relevant consequences for efficacy of antiviral therapy and drug toxicity. At present, the scarce data on drug-drug interactions with TVR ${ }^{40}$ limit TVR use in clinical practice, particularly among aged patients and those with comorbidities in need of comedications.

\section{Areas of uncertainity Patients with advanced liver disease}

There is convincing evidence that, in patients with advanced liver diseases, both the safety and efficacy of TVR-based regimens are attenuated, compared to patients with mild fibrosis. The negative role of liver fibrosis on the outcome of triple therapy has important clinical implications, particularly with respect to retreatment with TVR regimens of patients with a prior null response who achieved an SVR in less than $30 \%$ of the cases, only. ${ }^{19}$ These disappointing numbers, as well as the relative lack of safety data in patients with bridging fibrosis/ cirrhosis, suggest that the decision to treat with TVR in this category of patients should be individualized and discussed in detail with the patient.

\section{IL28B}

Polymorphisms in the Interleukin 28B gene (IL28B) have been associated with predictions of achieving an SVR to PR, patients carrying the $\mathrm{CC}$ genotype having the highest chances to obtain viral eradication ${ }^{41}$ While across IL28B genotypes triple therapy appears to be superior to SOC, interestingly, the rates of SVR to triple therapy were attenuated in patients carrying the $\mathrm{T}$ allele. In the ADVANCE trial, $\mathrm{CC}$ carriers achieved more SVR than did CT and TT patients $(90 \%$ vs $71 \%$ vs $73 \%),{ }^{42}$ and according to a post hoc analysis of the PROVE-2 study, TVR12PR patients carrying the CC IL28B genotype had the highest chances of SVR, compared to T allele carriers (100\% vs 50\%). Optimization studies with TVR are in progress to demonstrate whether IL28B CC patients may benefit from a shortened triple-therapy regimen. 


\section{Lead-in phase}

The strong predictive power of RVR for a response to $\mathrm{PR}^{43,44}$ has expanded the argument for treating HCV patients with the sole dual therapy, with the ultimate goal of sparing AEs and costs related to DAA-based regimens. However, since sensitivity to interferon represents a relevant prerequisite of TVR efficacy, ultimately granting for the prevention of RAVs, the potential usefulness of a lead-in phase in TVRtreated patients has been explored as well. In REALIZE, no benefits for treatment outcome in terms of SVR or virological breakthrough rates were demonstrated with respect to the lead-in-based treatment (64\% vs 66\%), but patients with a previous null response to PR, who experienced $a \geq 1 \log _{10}$ decline at week 4 of lead-in, had better responses than those with a $<1 \log _{10}$ decline ( $85 \%$ vs 54\%). ${ }^{45}$ Current guidelines in France, Sweden, and Germany only endorse a lead-in to identify those patients with IL28B $\mathrm{CC}$ genotype and $\mathrm{a} \leq \mathrm{F} 2$ upon histology who could benefit from dual therapy with PR. ${ }^{46-48}$

\section{Conclusion}

There is conclusive evidence that the addition of TVR to a PR regimen leads to improved rates of SVR among adult patients with chronic HCV genotype 1 infection. The $30 \%$ gain in SVR rates provided by triple therapy, however, is somewhat counterbalanced by increased incidence of $\mathrm{AE}$ and costs, which has expanded the search for optimized algorithms based on pretreatment selection of patients, and standard duration of therapies in patients with positive predictors of a response to TVR.

\section{Disclosure}

The authors report no conflicts of interest in this work.

\section{References}

1. World Health Organization. Global alert and response: hepatitis C. Available from: http://www.who.int/csr/disease/hepatitis/whocdscsrlyo 2003/en/index.html. Accessed December 2, 2010.

2. Shiratori Y, Imazeki F, Moryiama M, et al. Histologic improvement of fibrosis in patients with hepatitis $\mathrm{C}$ who have sustained virological response to interferon therapy. Ann Intern Med. 2000;132:517-524.

3. Yoshida H, Arakawa J, Sata M, et al. Interferon therapy prolonged life expectancy among chronic hepatitis C patients. Gastroenterology. 2002;123:483-491.

4. Shiratori Y, Ito Y, Yokosuka O, et al. Antiviral therapy for cirrhotic hepatitis C: association with reduced hepatocellular carcinoma development and improved survival. Ann Intern Med. 2005;142:105-114.

5. Rincon D, Ripoll C, Lo Iacono O, et al. Antiviral therapy decreases hepatic venous pressure gradient in patients with chronic hepatitis $\mathrm{C}$ and advanced fibrosis. Am J Gastroenterol. 2006;101:2269-2274.

6. Bruno S, Stroffolini T, Colombo M, et al. Sustained virological response to Interferon-alpha is associated with improved outcome in HCV-related cirrhosis: a retrospective study. Hepatology. 2007;45:579-587.
7. Veldt BJ, Heathcote EJ, Wedemeyer H, et al. Sustained virological response and clinical outcomes in patients with chronic hepatitis $\mathrm{C}$ and advanced fibrosis. Ann Intern Med. 2007;147:677-684.

8. Bruno S, Crosignani A, Facciotto C, et al. Sustained virological response prevents the development of esophageal varices in compensated, Child-Pugh class A HCV-induced cirrhosis. A twelve-year prospective follow-up study. Hepatology. 2010;51:2069-2076.

9. Cardoso AC, Moucari R, Figueiredo-Mendes C, et al. Impact of peginterferon and ribavirin therapy on hepatocellular carcinoma: incidence and survival in hepatitis $\mathrm{C}$ patients with advanced fibrosis. J Hepatol. 2010;52:652-657.

10. D'Ambrosio R, Aghemo A, Rumi MG, et al. The course of esophageal varices in patients with hepatitis $\mathrm{C}$ cirrhosis responding to interferon/ ribavirin therapy. Antivir Ther. 2011;16:677-684.

11. Manns MP, McHitchison JG, Gordon SC, et al. Peginterferon-alfa2b plus ribavirin compared with interferon-alfa2b plus ribavirin for initial treatment of chronic hepatitis C: a randomized trial. Lancet. 2001;358:958-965.

12. Fried MW, Shiffman ML, Reddy KR, et al. Peginterferon-alfa2a plus ribavirin for chronic hepatitis C infection. $N$ Engl J Med. 2002;347:975-982.

13. Hadziyannis SJ, Sette H, Morgan TR, et al. Peginterferon-alpha2a and ribavirin combination therapy in chronic hepatitis $\mathrm{C}$ : a randomized study of treatment duration and ribavirin dose. Ann Intern Med. 2004;140:346-355.

14. McHutchison JG, Everson GT, Gordon SC, et al. Telaprevir with peginterferon and ribavirin for chronic HCV genotype 1 infection. N Engl J Med. 2009;360:1827-1838.

15. Hézode C, Forestier N, Dusheiko G, et al. Telaprevir and peginterferon with or without ribavirin for chronic HCV infection. $N$ Engl J Med. 2009;360:1839-1850.

16. McHutchison JG, Manns MP, Muir AJ, et al. Telaprevir for previously treated chronic HCV infection. N Engl J Med. 2010;362:1292-1303.

17. Jacobson IM, McHutchison JG, Dusheiko G, et al. Telaprevir for previously untreated chronic hepatitis C infection. NEngl J Med. 2011; 364:2405-2416.

18. Sherman KE, Flamm SL, Afdhal NH, et al. Response-guided telaprevir combination treatment for hepatitis C virus infection. $N$ Engl J Med. 2011;365:1014-1024.

19. Zeuzem S, Andreone P, Pol S, et al. Telaprevir for retreatment of HCV infection. N Engl J Med. 2011;364:2417-2428.

20. Pawlotsky JM, Chevaliez S, McHutchison JG. The hepatitis C virus life cycle as a target for new antiviral therapies. Gastroenterology. 2007;132:1979-1998.

21. Rong L, Perelson AL. Treatment of hepatitis C virus infection with interferon and small molecule direct antivirals: viral kinetics and modelling. Crit Rev Immunol. 2010;30:131-148.

22. Bühler S, Bartenschlager R. New targets for antiviral therapy of chronic hepatitis C. Liver International. 2012;32:9-16.

23. Lange CM, Sarrazin C, Zeuzem S. Review article: specifically targeted anti-viral therapy for hepatitis $\mathrm{C}-\mathrm{a}$ new era in therapy. Aliment Pharmacol Ther. 2010;32:14-28.

24. Reeskin HW, Zeuzem S, Weegink CJ, et al. Rapid decline of viral RNA in hepatitis C patients treated with VX-950: a phase Ib, placebocontrolled, randomized study. Gastroenterology. 2006;131: 997-1002.

25. Prati GM, Aghemo A, Rumi MG, et al. Hyporesponsiveness to PegIFN $\alpha 2 \mathrm{~b}$ plus ribavirin in patients with hepatitis C-related advanced fibrosis. J Hepatol. 2012;56:341-347.

26. Lange CM, Zeuzem S. IL28B single nucleotide polymorphism in the treatment of chronic hepatitis C. J Hepatol. 2011;55:692-701.

27. Sarrazin C, Schwendy S, Möller B, et al. Improved responses to pegylated interferon alfa-2b and ribavirin by individualizing treatment for 24-72 weeks. Gastroenterology 2011;141:1656-1664.

28. Aghemo A, Degasperi E, Colombo M. Directly acting antivirals for the treatment of chronic hepatitis C: Unresolved topics from registration trials. Dig Liver Dis. In press 2012. 
29. Poynard T, Colombo M, Bruix, et al. Peginterferon alfa- $2 b$ and ribavirin: effective in patients with hepatitis $\mathrm{C}$ who failed interferon alfa/ribavirin therapy. Gastroenterology. 2009;136:1618-1628.

30. Shiffman ML, Di Bisceglie AM, Lindsay KL, et al. Peginterferon-alfa2a and ribavirin in patients with chronic hepatitis $\mathrm{C}$ who have failed prior treatment. Gastroenterology. 2004;126:1015-1023.

31. Forestier N, Zeuzem S. Triple therapy with Telaprevir: results in hepatitis $\mathrm{C}$ virus-genotype 1 infected relapsers and non-responders. Liver Int. 2012;32(Suppl 1):44-50.

32. Bedossa P, Poynard T. An algorithm for the grading of activity in chronic hepatitis C. Hepatology. 1996;24:289-293.

33. Hèzode C, Dorival C, Zoulim F, et al. Safety of telaprevir or boceprevir in combination with peginterferon alfa/ribavirin, in cirrhotic nonresponders. First results of the French early access program (ANRS CO20-CUPIC) in real-life setting. Presented at the French national liver meeting, in Paris, France, on September 28-October 1, 2011.

34. Sulkowski M, Reddy KR, Afdhal NH, et al. Anemia has no effect on efficacy outcomes in treatment-naïve patients who received telaprevirbased regimen in ADVANCE and ILLUMINATE phase 3 studies. J Hepatol. 2011;54:S195.

35. Rong L, Dahari H, Ribeiro RM, Perelson AS. Rapid emergence of protease inhibitor resistance in hepatitis C virus. Sci Transl Med. 2010;2:30-32.

36. Forestier N, Reesink HW, Weegink CJ, et al. Antiviral activity of telaprevir (VX-950) and peginterferon alfa-2a in patients with hepatitis C. Hepatology. 2007;46:640-648.

37. Sarrazin C, Kieffer TL, Bartels D, et al. Dynamic hepatitis C virus genotypic and phenotypic changes in patients treated with the protease inhibitor telaprevir. Gastroenterology. 2007;132:1767-1777.

38. Kieffer TL, Sarrazin C, Miller JS, et al. Telaprevir and pegylated interferon-alpha-2a inhibit wild-type and resistant genotype 1 hepatitis $\mathrm{C}$ virus replication in patients. Hepatology. 2007;46:631-639.

39. Susser S, Vermehren J, Forestier N, et al. Analysis of long-term persistence of resistance mutations within the hepatitis C virus NS3 protease after treatment with telaprevir or boceprevir. J Clin Virol. 2011;52:321-327.
40. eMedFusion, The University of Liverpool. Hep Drug Interactions. Available from: http://www.hep-druginteractions.org. Accessed Jun 28, 2012

41. Thompson AJ, Muir AJ, Sulkowski MS, et al. Interleukin-28B polymorphism improves viral kinetics and is the strongest pretreatment predictor of sustained virologic response in genotype 1 hepatitis C virus. Gastroenterology. 2010;139:120-129.

42. Jacobson IM, Catlett I, Marcellin P, et al. Telaprevir substantially improved SVR rates across all IL28B genotypes in the advance trial. J Hepatol. 2011;54:S543.

43. Martinot-Peignoux M, Maylin S, Moucari R, et al. Virological response at 4 weeks to predict outcome of hepatitis $\mathrm{C}$ treatment with pegylated interferon and ribavirin. Antivir Ther. 2009;14:501-511.

44. Fried MW, Hadziyannis SJ, Shiffman ML, Messinger D, Zeuzem S. Rapid virological response is the most important predictor of sustained virological response across genotypes in patients with chronic hepatitis C virus infection. J Hepatol. 2011;55:69-75.

45. Foster G, Zeuzem S, Andreone P, et al. Subanalysis of the telaprevir lead-in arm in the REALIZE study: response at week 4 is not a substitute for prior null response categorization. $J$ Hepatol. 2011;54(Suppl 1):6A

46. Prise de position de l'Association Française pour l'Etude du Foie (AFEF) sur les trithérapies (Peg-IFN + ribavirine + inhibiteur de protéase) dans la prise en charge des malades atteints d'hépatite chronique $\mathrm{C}$.

47. Referensgruppen för Antiviral Terapi (Rav). Läkemedelsbehandling av hepatit $\mathrm{C}$ virusinfektion hos vuxna och barn - uppdaterad rekommendation. Swedish Consensus Guidelines 2011.

48. Sarrazin C, Berg T, Cornberg M, et al. Expertenempfehlungen zur Triple-Therapie der HCV Infektion mit Boceprevir und Telaprevir. Z Gastroenterol. 2011;49:1-16.
Biologics: Targets \& Therapy

\section{Publish your work in this journal}

Biologics: Targets \& Therapy is an international, peer-reviewed journal focusing on the patho-physiological rationale for and clinical application of Biologic agents in the management of autoimmune diseases, cancers or other pathologies where a molecular target can be identified. This journal is indexed on PubMed Central, CAS, EMBase, Scopus

\section{Dovepress}

and the Elsevier Bibliographic databases. The manuscript management system is completely online and includes a very quick and fair peerreview system, which is all easy to use. Visit http://www.dovepress com/testimonials.php to read real quotes from published authors. 